\title{
Prevalence of Carpal Tunnel Syndrome among Computer Users of in the Mosul University
}

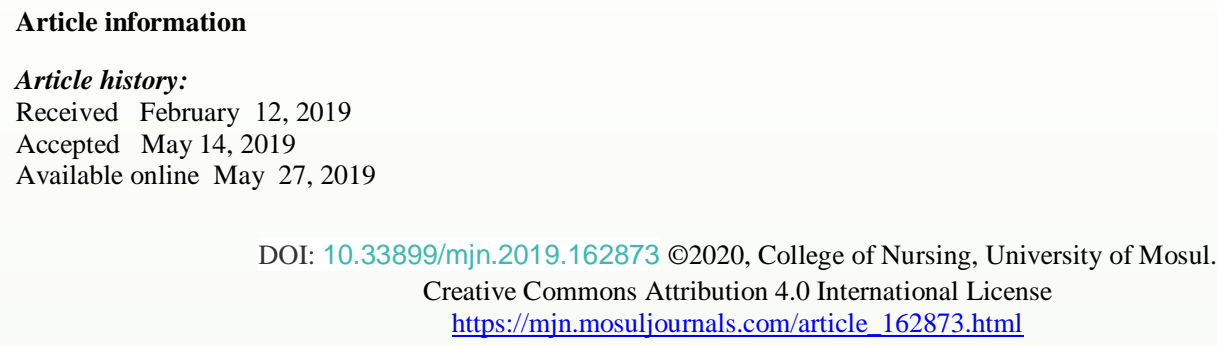

\section{Bashar J. Aljuwary ${ }^{1}$,} Haifa H. Altaie ${ }^{3}$,
Isra N. Alkallak $^{2}$,
Suha J. Abdullatif

\begin{abstract}
Aim :To study the prevalence of carpal tunnel syndrome among over use of computer mouse in Mosul University employees.

Method: A cross sectional design study was adopted in a purposive sample of (138) employees using computer in a daily working hours at Mosul University, the sample include both faculty members and administrators. Certain variables such as age, gender and the period of experience of computer work. The investigators use a clinical examination (a Phalen test, Pin Prick and Tournquit test) \& nerve conduction test for diagnosis of problem among participants.

Results: Female employees uses computer more than males (92:46). The highest prevalence of carpal tunnel syndrome was found among age group (31-35) with (31\%), and among females more than males (2:1). Bachelor employee represent $55.07 \%$ of the study sample. The study also found that pregnancy was the most common risk factor among female participants while obesity was the major risk factor among male. The use of analgesia to relieve the symptoms was predominant measure among affected employees.
\end{abstract}

Recommendation: avoidance of repetitive trauma for the wrist or any continuous pressure created by excessive use of computer's mouse, and weight reduction.

\footnotetext{
${ }^{1}$ Assist prof./ Mosul University/ Nursing Collage / Clinical Dept.

${ }^{2}$ Ass. prof./Mosul University Nursing Collage / Basic Dept

${ }^{3}$ Ass. lecturer/Mosul University Nursing Collage/ Basic Dept

${ }^{4}$ lecturer/ Mosul University Nursing Collage / Clinical Dept.
} 


\section{Mosul Journal of Nursing, Vol. 7, No. 1, 2019 ( $37-43$ )}

\section{Introduction}

Carpal tunnel syndrome is an entrapment neuropathy that occurs when the median nerve at the wrist is compressed by a thickened flexor tendon sheath, skeletal encroachment, edema or soft tissue mass. Christensen \& Kockrow (2003), Phillip (2010), Smeltzers \& Siddartha (2010).

Carpal tunnel syndrome is an important cause of pain and functional impairment of the hand due to compression of median nerve, usually people affected at $3^{\text {rd }}$ and $4^{\text {th }}$ decades of their life, women affected three times more than men, about $0.5 \%$ of general population reports being diagnosed with carpal tunnel syndrome, especially with world filled with computers and video games. Tamir \& Zakaria (2016), Young etal, (2018). Carpal tunnel syndrome presented as discomfort, numbness, pins, burning and some times pain, these symptoms tend to be worse at

\section{Aim of the Study}

The main aim of the study is to estimate the prevalence of carpal tunnel syndrome among computer users in Mosul University while the specific objectives of the study were:

1- To estimate prevalence of carpal tunnel syndrome among computer users in Mosul University in regard to certain variables such as age, gender, period of experience computer work in a day.

2- To verify the risk factors for carpal tunnel syndrome among this group.

3- To identify the relieving measures taken by the affected group.

\section{Methodology}

A cross sectional study design was adopted at Mosul University on a purposive sample of (138) participants included in this study with a criteria of excessive use of computer mouse during daily work. The employees whose jobs are not related to the computer were excluded from the sample, the sample include both faculty members and administrators 46 night, in severe case the hand muscle become weakened making difficulty to grip objects. Demiryurek \& Gundogdu (2018), Soloman (2010).

Experiments on the effect of positions of fingers, wrist and forearm comparable to the positions common in computer use have shown that carpal tunnel syndrome increases but not to levels generally believed to be harmful. Lewis-Heitkemper (2001). Surprisingly, mean carpal tunnel syndrome levels between $28-33 \mathrm{mmHg}$ where observed when study participants were dragging or clicking with the mouse. Lower values were found with the hand static on the mouse. Keith (2009). Although the experiment has never been repeated the findings indicate a possible pathophysiological mechanism for carpal tunnel syndrome among heavy mouse users.

National Institute of Neurological Disorders \& Skin (2014).

males and 92 females. Data were collected in a period of 2 months duration from October to the end of November 2018.

To achieve the desired aim and the objectives of the present study a special tool was implemented, this tool was intended by the investigators through use different literature and it is consist mainly four parts.

1- Socio-demographic data of the sample include age, gender, educational levels, type of work, period of experience computer work.

2- A checklist of the main clinical signs and symptoms (Yes, No) for the diagnosis clinical of carpal tunnel syndrome. The clinical tests used were Phalen test, Pin Prick test and Tourniquet test. This clinical examination conducted by specialist orthopedic surgeon to diagnose affected persons. To confirm the diagnosis of nerve compression conduction test. American Academy of orthopedic surgeons (2014).

3- Carpal tunnel syndrome risk factors. 


\section{Mosul Journal of Nursing, Vol. 7, No. 1, 2019 ( $37-43$ )}

4- The main relieving measures taken by the affected members of the study sample. used a sensitive and specific Carpal tunnel syndrome case definition (including NCT) and precise estimates of exposure with the use of questionnaires and direct measurements.

Validity was obtained, the reliability was achieved, by test and retest of a sample of
10 participants pilot study whose and reliability to detect validation of the instrument suitable to the present study excluded from the sample of the study. Computation of correlation coefficient was achieved, (r) revealed a value of 0.8 . Data were analyzed by using SPSS software version 17. Frequency, percentage and prevalence rate.

\section{Results}

Table (1): distribution of the study sample according to their socio-demographic data.

\begin{tabular}{|c|c|c|}
\hline Age Groups & No. & Percentage $\%$ \\
\hline $21-25$ & 7 & 5 \\
\hline $26-30$ & 37 & 26.8 \\
\hline $31-35$ & 44 & 31.9 \\
\hline $36-40$ & 25 & 18.1 \\
\hline $41-45$ & 17 & 12.3 \\
\hline 46 and more & 8 & 5.8 \\
\hline Total & 138 & 100 \\
\hline Gender & No. & Percentage $\%$ \\
\hline Male & 46 & 33.33 \\
\hline Female & 92 & $\overline{666.66}$ \\
\hline Total & 138 & 100 \\
\hline Educational Levels & No. & Percentage $\%$ \\
\hline Intermediate & 3 & 2.1 \\
\hline Secondary School & 6 & 4.4 \\
\hline Institute & 29 & 21 \\
\hline Bachelor & 76 & 55.07 \\
\hline Post Graduate & 24 & 17.4 \\
\hline Total & 138 & 100 \\
\hline Types of Work & No. & Percentage $\%$ \\
\hline Faculty Member & 24 & 18 \\
\hline Administrator & 114 & 82 \\
\hline Total & 138 & 100 \\
\hline Marital Status & No. & Percentage $\%$ \\
\hline Married & 98 & 71 \\
\hline Unmarried & 40 & 28 \\
\hline
\end{tabular}

Table (2): Prevalence of carpal tunnel syndrome among university employees in regard to their age.

\begin{tabular}{|c|c|c|c|c|c|}
\hline \multirow[t]{2}{*}{ Age } & \multicolumn{2}{|c|}{ Affected } & \multicolumn{2}{|c|}{ Non affected } & \multirow[t]{2}{*}{ Prevalence } \\
\hline & No. & $\begin{array}{c}\text { Percentage } \\
\%\end{array}$ & No. & $\begin{array}{c}\text { Percentage } \\
\%\end{array}$ & \\
\hline
\end{tabular}


Mosul Journal of Nursing, Vol. 7, No. 1, 2019 ( $37-43$ )

\begin{tabular}{|c||c||c||c||c||c|}
\hline $21-25$ & 7 & 5 & 0 & 0 & 1.9 \\
\hline \hline $26-30$ & 17 & 12.3 & 20 & 14.4 & 4.7 \\
\hline \hline $31-35$ & 14 & 10.1 & 30 & 21.7 & 3.8 \\
\hline \hline $36-40$ & 9 & 6.5 & 16 & 11.5 & 2.4 \\
\hline \hline $41-45$ & 3 & 2.1 & 14 & 10.14 & 0.83 \\
\hline \hline 46 and more & 0 & 0 & 8 & 5.79 & 0 \\
\hline \hline Total & 50 & & 88 & & \\
\hline
\end{tabular}

Table (3): Prevalence of carpal tunnel syndrome among Mosul University employees in regard to gender.

\begin{tabular}{|c||c||c||c|c||c||}
\hline \hline \multirow{2}{*}{ Gender } & \multicolumn{2}{|c||}{ Affected } & \multicolumn{2}{c||}{ Non affected } & \multirow{2}{*}{ Prevalence } \\
\cline { 2 - 5 } & No. & $\begin{array}{c}\text { Percenta } \\
\text { ge \% }\end{array}$ & No. & $\begin{array}{c}\text { Percentage } \\
\%\end{array}$ & \\
\hline \hline Male & 11 & 7.97 & 36 & 26.08 & 3.04 \\
\hline \hline Female & 39 & 28.2 & 52 & 37.6 & 10.8 \\
\hline \hline Total & 50 & & 88 & & \\
\hline
\end{tabular}

Table (4): Prevalence rate of carpal tunnel syndrome among Mosul University employees regarding their period of experiencing computer in an usual day work.

\begin{tabular}{|c||c||c||c|c|c||}
\hline $\begin{array}{c}\text { Period of } \\
\text { Experiencing } \\
\text { Computer Work }\end{array}$ & No. & Percentage \% & No. & Percentage \% & Prevalence \\
\cline { 2 - 5 } & 2 & 1.4 & 56 & 40.5 & 0.55 \\
\hline \hline \begin{tabular}{c}
$1-3$ hour daily \\
\hline $\begin{array}{c}4 \text { hour \& more } \\
\text { daily }\end{array}$
\end{tabular} & 48 & 34.7 & 32 & 23.1 & 13.2 \\
\hline \hline Total & 50 & & 88 & & \\
\hline
\end{tabular}

Table (5) Risk factors for carpal tunnel syndrome among university employees.

\begin{tabular}{|c|c|c|c|c|}
\hline \multirow{2}{*}{ Risk Factors } & \multicolumn{2}{|c|}{ Affected female } & \multicolumn{2}{|c|}{ Affected male } \\
\hline & No. & Percentage $\%$ & No. & Percentage $\%$ \\
\hline Pregnancy & 31 & 33 & & \\
\hline Trauma & 4 & 4.3 & 3 & 6.5 \\
\hline Diabetes Mellitus & 5 & 5.3 & 1 & 2.1 \\
\hline Hypertension & 28 & 30 & 3 & 6.5 \\
\hline Obesity & 17 & 18 & 6 & 13 \\
\hline Thyroid Dysfunction & 12 & 13 & 3 & 6.5 \\
\hline
\end{tabular}

Table (6) Results of nerve condition test of the employees according of severity

\begin{tabular}{|c|c||c||c||c||}
\hline \multirow{2}{*}{ Result of N.C.T. } & \multicolumn{2}{|c||}{ Affected } & \multicolumn{2}{c|}{ Not Affected } \\
\cline { 2 - 5 } & No. & Percentage \% & No. & Percentage \% \\
\hline \hline Normal & - & - & 88 & 63.76 \\
\hline \hline Mild & 9 & 6.52 & - & - \\
\hline \hline Modarat & 37 & 26.81 & - & - \\
\hline \hline Severe & 4 & 2.89 & - & - \\
\hline
\end{tabular}


Table (7): Relieving measures taken by affected employees.

\begin{tabular}{|l||c||c||}
\hline \multicolumn{1}{|c||}{ Measures } & No. & Percentage \% \\
& & 50 \\
\hline \hline Medications\& Analgesia & 25 & 34 \\
\hline \hline Anti-inflammatory & 17 & 10 \\
\hline \hline Use Wrist Splint & 5 & 14 \\
\hline \hline Take Period of Rest & 7 & 18 \\
\hline \hline Use of other Hand & 9 & \\
\hline
\end{tabular}

\section{Discussion:}

The epidemiological evidence of an association between computer use and carpal tunnel syndrome is inconsistent. The association between computer work and Carpal tunnel syndrome had important limitations. Thus, a definitive study that clarifies the relationship between computer use and carpal tunnel syndrome has not been conducted yet. Based on evaluation of study design, sample sizes and response rates, case definitions and the exposure information, the studies yield valid inferences, the study very intense computer work was represented (e.g. data entry, graphical work) .It observed an association between mouse use and symptoms of carpal tunnel syndrome in the median nerve distribution area in both the cross sectional analyses. The association was statistically significant for participants reporting more than $20 \mathrm{~h} / \mathrm{w}$ of mouse use. Table 1: shows that majority of the study sample $(31 \%)$ within the age group (31-35) years. Male to female ratio was $1: 2$, and $(53 \%)$ of sample graduated from college, $(82 \%)$ were administrators. Married participant more than others. The dominant hand is usually affected first and produces the most severe pain. Persons with diabetes or other metabolic disorders that directly affect the body's nerves and make them more susceptible to compression are also at high risk. Carpal tunnel syndrome usually occurs only in adults. In Table 2: demonstrate the highest prevalence rate of carpal tunnel syndrome was significantly found among the age group of (26-30) year. This age regarded as the beginning of the practical stage of life. While Table 3: shows that carpal tunnel syndrome more prevalent among females employees. It is 2 times more than male. This may be due to smaller size tunnel and additional daily work at home which may aggravate the symptoms, this correspond with other study, women are three times more likely than men to develop carpal tunnel syndrome, perhaps because the carpal tunnel itself may be smaller in women than in men. Jone etal (2008). Table 4: revealed that carpal tunnel syndrome more prevalent among excessive users of the computer for more than 4 hours ( $2 / 3$ times of their work), especially when they use computer's mouse which may aggravate the condition and cause pain of the used hand. When statistical tests were applied to the results a significant positive association was observed for the association between mouse use and carpal tunnel syndrome. However, the significant association was unadjusted for potentially confounding risk factors, e.g. age Shiri etal (2012). Work tasks demanding handgrip with high forces or the use of vibrating tools are associated with carpal tunnel syndrome. The association is stronger if these work tasks are accompanied by repetitive movements of the hand or wrist. Huisstede etal (2010). The risk of developing carpal tunnel syndrome is not confined to people in a single industry or job, but is especially common in those performing assembly line work - manufacturing, sewing, finishing, cleaning, and meat, poultry, or fish packing. In fact, carpal tunnel syndrome is three times more common among assemblers than among data-entry personnel. Keith (2010). In the Tables (5): The pregnancy was the most common risk predispose for carpal tunnel syndrome, In 


\section{Mosul Journal of Nursing, Vol. 7, No. 1, 2019 ( $37-43$ )}

addition to obesity and the associated hypertension. Rozali etal (2012). In males participant the most common risk factors were obesity, trauma and hypertension.

\section{Conclusion}

In summary, because of insufficient quality, bias, lack of consistency and statistical power evidence is insufficient to conclude that computer work (mouse and keyboard) causes carpal tunnel syndrome. As a consequence, this condition cannot be recognized as an occupational injury because of computer work. Carpal tunnel syndrome is a reasonably common disorder in people of working age, although its diagnosis is not without elements of difficulty and controversy. The disorder can cause functional

\section{Recommendations}

1- For the prevention of the condition, avoidance of repetitive trauma for the hand, that is created by excessive use of computer's moue.

2- Dealing with risk factors accordingly, by controlling body weight, treating systemic illness like diabetes mellitus and hypertension.

3- Follow certain preventive measures when there is a repetitive movement or frequent trauma for the wrist or hand created by excessive use of mouse:

a. Avoid putting hand on hard surface for long time.

b. Sitting position should be comfortable and suitable to the activity performed.

c. Relieving discomfort by performing hand exercise .

Acknowledgment: Special thanks to all members in Mosul University employees who participated in the study.

\section{References}

1.Christensen B, and Kockrow E., (2003), Adult Heath Nursing. Carpal Tunnel Syndrome. Fourth Edition. Mosby, 158159.

2.Smeltzers, Bare B and Siddartha S., (2010), Textbook of Medical Surgical Nursing. Carpal Tunnel syndrome,
The table shows that $50 \%$ of affected employees use analgesic drugs to relieve symptoms of carpal tunnel syndrome in addition to other measures.

handicap and is compensable under some circumstances when occupationally related. Clear associations have been established between carpal tunnel syndrome and workplace activities involving exposure to hand-transmitted vibration and/or repeated and forceful movements of the hand/wrist. Symptoms may be avoidable if good ergonomic practices are followed, and control of mechanical risk factors in the workplace can aid rehabilitation of the affected worker. In vibration-induced carpal tunnel syndrome, a change of occupation is often indicated

Eleventh Edition. Lippincott and wilkins, 2052-2053.

3. Phillip E, Wrigh II., (2010), Carpal Tunnel, Ulnar Tunnel and Stenosing Tenosynovitis. Campbell's Operative Orthopedics. $12^{\text {th }}$ Edition, Mosby, 42854286.

4.Siguard c, Sandzen JR., 2003, Health Information $\mathrm{ABC}$ of Health. Carpal Tunnel Syndrome. Published by BUPA; Health Information team U.K. Internet June.

5.Inoue G, Ipsen., 2003, American Academy of Orthopedic Surgeons, American association of Orthopedic Surgeons. Carpal Tunnel Syndrome U.S.A. March.

6.Arcy D, Christopher A, Mc Gee, Steven MD., 2000, Does this patient have carpal tunnel syndrome-Journal of American association JAMA-June; Vol. 283(23). 3110-3117.

7.Hicks Rob., 2003, your health, Health at work-physical health, Carpal Tunnel Syndrome, Internet.

8.BBC-health at work- Carpal Tunnel Syndrome- November 2003 Internet.

9.Soloman L, Warwick Dj and Nayagam S., 2010, Apley's System of orthopedics \& Fractures (Carpal Tunnel Syndrome) $9^{\text {th }}$ Edition Arnolds U.S.A.

10. Lewis-Heitkemper. Dirksen., 2001, Medical Surgical Nursing. Assessment \& management of clinical problem- $5^{\text {th }}$ edition U.S.A., Mosby; 1765. 
11.Keith MW., 2009, American Academy of Orthopaedic Surgeons clinical practice guidelines on the diagnosis of carpal tunnel syndrome. J Bone Joint Surg Am., 91(10):2478-2479.

12.National Institute of Neurological Disorders\& Skin CTS Facts Shee 2014.

13.American Academy of orthopedic surgeons CTS 2014.

14.Jone $\mathrm{F}$ Thomson, Fred Ger and Isan Atroshi., 2008, CTS and the use of computer mouse and keyboard :Asystemic review BMG Musculoskeletal Disord., 9:134.

15.Shiri R1, Miranda H, Heliövaara M, Viikari-Juntura E., 2012, Physical work load factors and carpal tunnel syndrome: a population-based study. J Occup

Environ Med. Feb; 54(2):198-201.

16.Huisstede BM1, Hoogvliet P, Randsdorp MS, Glerum S, vanMiddelk M, Koes BW., 2010, Effectiveness of nonsurgical treatments--a systematic Arch Phys Med Rehabil. Jul, 91(7):981-1004.

17. Keith MW., 2010, American Academy of Orthopaedic Surgeons clinical practice guidelines on the treatment of carpal tunnel syndrome. $J$ Bone Joint Surg Am. 92(1):218-219.

18.Rozali ZI, Noorman FM, De Cruz PK, Feng YK, Razab HW, Sapuan J, Singh R,

Sikkandar FM., 2012, Impact of carpal tunnel syndrome on the expectant woman's life. Asia Pac Fam Med. Jan 30; 11(1):1. 